\title{
O DIREITO PENAL DO INIMIGO E A (IN) COMPATIBILIDADE DO ESTADO DEMOCRÁTICO DE DIREITO
}

THE ENEMY'S CRIMINAL LAW AND THE (IN) COMPATIBILITY OF THE DEMOCRATIC STATE OF LAW

Diógenes Alves de OLIVEIRA ${ }^{1}$

ISSUE DOI: $10.21207 / 1983.4225 .350$

\section{RESUMO}

O presente trabalho tem como objetivo conceituar o Direito Penal do Inimigo em um Estado Democrático de Direito. Direito Penal do Inimigo é um novo enfoque do Direito Penal com um viés de Política Criminal. Possui uma forte tendência de modelo dissuasório, sendo também conceituado como um movimento Neopunitivista. Como um movimento recente de política criminal e de grande ascensão, principalmente depois dos atentados de 11 de setembro, sua doutrina tem servido de base para legitimar mitigações nos direitos do cidadão. Ao analisar os argumentos contrários ao Direito Penal do Inimigo, foi possível verificar os contra argumentos constitucionais que relativizam as concepções desfavoráveis à teoria. Por fim, foi possível verificar uma forte base teórica de Jakobs em sua teoria em que

\footnotetext{
${ }^{1}$ Graduado em Direito pela UDF (Brasília), Pós-Graduação em Criminologia, Política Criminal e Segurança Pública pela LFG e Universidade Anhanguera Uniderp, Servidor Público na Área de Segurança há 10 anos. E-mail: diogenesdp@gmail.com
} 
os riscos inerentes a sua teoria andam juntos com a existência do próprio Estado Democrático de Direito.

Palavras-Chave: Direito Penal do Inimigo, Estado Democrático de Direito, hermenêutica constitucional.

\section{INTRODUÇÃO}

A data de 11 de setembro de 2001 será sempre lembrada quando o mundo parou e assustado viu na tela das televisões um ataque direto aos EUA. Esse país que sempre lutou contra as ditaduras e divulgou a democracia como única forma condizente de garantir aos seus cidadãos os direitos inerentes à dignidade humana em um mundo globalizado. Dentre eles, destaca-se a liberdade como um dos pressupostos básicos. Seus habitantes viram assustados o seu país sendo atacado, algo que não acontecia desde Pearl Harbor. Todavia neste episódio, duas diferenças marcantes: desta vez o ataque não foi feito por aviões militares, mas por aviões civis, os quais tinham sido sequestrados e o objetivo não foi alvo militar, mas alvos civis, símbolos da nação de um país democrático.

Um ataque vindo de "dentro do próprio país" criou uma sensação de insegurança absoluta da sociedade. Como forma de restabelecer a tranquilidade, o presidente George W. Bush assinou o decreto USA Act Patriot, o qual permite, entre outras medidas, que órgãos de segurança e de inteligência dos EUA interceptem ligações telefônicas e e-mails de organizações e pessoas supostamente envolvidas com terrorismo, sem necessidade de qualquer autorização da Justiça, sejam elas estrangeiras ou americanas.

Neste contexto, um novo movimento neopunitivista teve grande ascensão: o Direito Penal do Inimigo. Concebido por Gunther Jakobs, esse modelo dissuasório é um novo enfoque do Direito Penal com um viés de Política Criminal, determinando duas espécies de indivíduos perante o sistema penal: o cidadão comum, o qual terá todas as garantias processuais e matérias de um Estado de Direito e o inimigo, o qual será tratado como um objeto e não como uma pessoa que tem os mesmos direitos de um cidadão comum.

Esse modelo de Direito Penal foi e é duramente criticado, com reações emotivas e muitas vezes sem uma análise detida do que realmente seja o Direito Penal do Inimigo, conforme denuncia GRECO: 
Poucos temas provocam tomadas de posição tão decididas e apaixonadas quanto a ideia do "direito penal do inimigo". Mas, curiosamente, a introdução do conceito por Jakobs duas décadas atrás ou mal foi notada, ou foi aplaudida como uma "impressionante defesa da liberdade dos cidadãos." Já a retomada do conceito por seu criador em algumas publicações mais recentes caiu como uma bomba sobre a ciência do direito penal, cujo estrondo só está sendo superado pelas veementes reações que a idéia está gerando. ${ }^{2}$

Portanto, faz-se necessária uma análise mais precisa deste modelo frente a um Estado Democrático de Direito, em que uma suposta incompatibilidade pode ser apenas uma visão deturpada do real efeito do Direito Penal do Inimigo em um Estado, ligada mais a questões pré-concebidas do que uma análise fria deste Direito que propõe separar o cidadão do inimigo igual o fazendeiro separa o joio do trigo. Esse é o objetivo deste trabalho, tentando não se posicionar sobre o tema e analisar a compatibilidade da estrutura do Estado a um Direito Penal do Inimigo.

\section{UM BREVE ESTUDO DAS DEFINIÇÕES DOUTRINÁRIAS DE ESTADO DEMOCRÁTICO DE DIREITO E DIREITO PENAL DO INIMIGO}

O Estado Democrático de Direito, também denominado como Estado Constitucional, pode ser definido como a submissão do Poder Estatal às determinações contidas na Constituição, sendo esta derivada de uma soberania popular, ou seja, a participação do povo no poder político de condução do Estado.

Neste sentido, o Estado tem que garantir os direitos do cidadão, seja de forma negativa, permitindo a liberdade individual, seja de forma ativa, como o direito à saúde e à segurança. Segundo Bernardo Gonçalves Fernandes, o Estado Democrático de Direito seria um novo paradigma de Estado e de Direito:

\footnotetext{
${ }^{2}$ GRECO, Rogério. Direito Penal do Equilíbrio. 8.ed. Rio de Janeito: Impetus, 2015. p. 213.
} 
Na realidade, o Estado Democrático de Direito é muito mais que um princípio, configurando-se em verdadeiro paradigma - isto é, pano de fundo de silêncio - que compõe e dota de sentido as práticas jurídicas contemporâneas. ${ }^{3}$

Em relação ao Direito Penal do Inimigo, Gunther Jakobs, doutrinador alemão, parte da ideia que o direito penal tem como função primordial proteger a norma e só reflexamente os bens jurídicos. Para ele, o fato de proteger determinados bens, de garantir a credibilidade do próprio sistema é que permite que pessoas se determinem de acordo com a lei.

Assim, permite que a norma penal possa determinar certas condutas como criminosas mesmo que não lesem bens jurídicos, o que em tese poderia ofender o princípio da ofensividade, pois a única necessidade para esta tipificação é que a mesma esteja contida na norma de convivência social.

Portanto, a teoria de Jakobs em relação à função do direito penal permite a criminalização de condutas que apenas geram algum tipo de perigo, mesmo que esse não chegue a atingir o bem jurídico, ou seja, criminaliza o potencial risco ou perigo de lesão. Essa base teórica será fundamental para garantir sua teoria do Direito Penal do Inimigo.

Jakobs, utilizando os estudos sociológicos de LUHMANN em relação às expectativas cognitivas, divide o Direito Penal em dois sistemas diferentes, propostos para compreender duas categorias de seres humanos também considerados diferentes em relação a essas expectativas cognitivas - os cidadãos e os inimigos.

a) o cidadão é autor de crimes normais, que preserva uma atitude de fidelidade jurídica intrínseca, uma base subjetiva real capaz de manter as expectativas normativas da comunidade, conservando a qualidade de pessoa portadora de direitos, porque não desafia o sistema social;

b) o inimigo é autor de crimes de alta traição, que assume uma atitude de insubordinação jurídica intrínseca, uma base subjetiva real capaz de produzir um

\footnotetext{
${ }^{3}$ FERNANDES, Bernardo Gonçalves. Curso de direito constitucional. Salvador. Juspodivm, 2015. p. 288.
} 
estado de guerra contra a sociedade, com a permanente frustração das expectativas normativas da comunidade, perdendo a qualidade de pessoa portadora de direitos, porque desafia o sistema social. ${ }^{4}$

O inimigo é o não-pessoa, é o indivíduo que não oferece expectativa cognitiva positiva sobre seu comportamento no meio social, ou seja, é um perigo iminente a sociedade, uma bomba-relógio pronta para explodir. Neste sentido, o sistema penal para o cidadão estaria vinculado a fatos passados, após o cometimento do crime, um direito penal da culpabilidade, enquanto que para o inimigo, a punição estaria vinculada à sua periculosidade ligada a fatos que futuramente possa cometer.

"Um indivíduo que não se deixa coagir a viver num estado de civilidade, não pode receber as bençãos do conceito de pessoa." Inimigos são "a rigor não-pessoas," lidar com eles não passa de "neutralizar uma fonte de perigo, como um animal selvagem." Características do direito penal do inimigo são uma extensa antecipação das proibições penais, sem a respectiva redução da pena cominada, e a restrição das garantias processuais do estado de direito. ${ }^{5}$

Dessa forma, Jakobs distingue o direito penal do cidadão do direito penal do inimigo e ainda afirma que não estava inovando uma vez que jus filósofos do passado, como Rousseau, Hobbes e Kant já reconheciam duas classes de indivíduos. Citando Rousseau, demonstra claramente que sua teoria parte do princípio de que o Estado não deve reconhecer direitos ao indivíduo o qual tem a intenção de "destruir" o próprio sistema de Estado.

São especialmente aqueles autores que fundamentam o Estado de modo estrito, mediante um contrato, entendem o delito no sentido de que o delinquente

\footnotetext{
${ }^{4}$ SANTOS, Juarez Cirino dos. O Direito penal do inimigo - Ou o Discurso do Direito Penal Desigual, Instituto de Criminologia e Política Criminal, ICPC, 2012. Disponível em http://icpc.org.br/wp-content/uploads/2012/05/direito_penal_do_inimigo.pdf. Acesso em 01/09/2015. p.5.

${ }^{5}$ GRECO, Rogério. Direito Penal do Equilíbrio. 8.ed. Rio de Janeito: Impetus, 2015, p. 218.
} 
infringe o contrato, de maneira que já não participa dos benefícios deste. ${ }^{6}$

Citando Hobbes afirma que o indivíduo que pratica determinadas condutas, está traindo o próprio Estado, voltando assim a um estado de natureza de selvagem, e que, portanto, não teria uma condição de cidadão:

Entretanto, a situação é distinta quando se trata de uma rebelião, isto é, de alta traição. Pois a natureza deste crime esta na rescisão da submissão, o que significa a uma recaída no estado de natureza...E aqueles que incorrem em tal delito não são castigados como súditos, mas como inimigos. ${ }^{7}$

Nesta perspectiva, o direito penal do cidadão mantém a vigência da norma, enquanto o direto penal do inimigo combate perigos. $\mathrm{O}$ cidadão não pode ser abandonado pelo ordenamento jurídico, pois tem o direito de voltar a ajustar-se com a sociedade. Por outro lado, o inimigo passa a não merecer o direito do cidadão, pois se tornou um mero indivíduo e, portanto, o estado não deve tratá-lo como pessoa, já que do contrário vulneraria o direito à segurança das demais pessoas. Ressalta-se que Jakobs não defende a premissa do direito penal para a proteção dos bens jurídicos principais, mas sim como forma de garantir o próprio sistema penal.

\section{ESTADO DEMOCRÁTICO DE DIREITO E DIREITO PENAL DO INIMIGO}

Um dos argumentos mais utilizados para rechaçar o Direito Penal do Inimigo é justamente afirmar que é incompatível com o Estado Democrático de Direito. Argumentam que este modelo de sistema penal não se coaduna principalmente quando se considera como base fundamental deste tipo de Estado, o princípio da dignidade humana.

Recentemente, assistimos aos episódios de tortura praticados por soldados americanos que humilhavam

\footnotetext{
${ }^{6}$ JAKOBS, Gunther; MELIÁ, Manuel Cancio. Direito penal do inimigo: noções e críticas. Porto Alegre: Livraria do Advogado Editora, 2012, p. 36 e 37.

${ }^{7}$ Id. p. 40 .
} 
os presos pertencentes ao exército iraquiano. Será que, mesmo tendo praticado as atrocidades reveladas pelos noticiários de jornal, aqueles presos poderiam receber o tratamento degradante que lhes era aplicado pelo exército vitorioso?

É claro que, por mais que sejamos esclarecidos, por mais que nos revoltemos com as cenas veiculadas pelos meios de comunicação, mostrando pessoas inocentes sendo mortas brutalmente pelos membros do exército iraquiano, até mesmo o soldado mais vil tem o direito de, ao ser preso, ver assegurados os seus direitos e garantias fundamentais. ${ }^{8}$

Todavia, um choque entre direitos fundamentais é inerente à amplitude do próprio direito e pela quantidade infinita de possibilidades de casos concretos. Neste sentido, nenhum direito fundamental possui um caráter absoluto, logo que, invariavelmente, chocar-se-á com o direito fundamental de outra pessoa. Portanto, são normas de realização de um bem jurídico na maior medida que as circunstâncias permitem, ou seja, da melhor forma possível.

Em um eventual confronto de princípios, será realizado um juízo de ponderação, em que um destes princípios/direitos fundamentais será afastado do caso concreto, mas não do ordenamento jurídico. O ministro Gilmar Mendes expõe que direitos fundamentais podem ser relativizados até mesmo por valores sociais, conforme se depreende do seguinte trecho:

As situações de embates entre princípios podem assumir tanto a forma de colisão de direitos fundamentais, como a de conflito entre um direito fundamental e um outro valor consagrado na Constituição, Veja-se, por exemplo, que o valor da saúde pública pode ensejar medidas restritivas da liberdade de ir e vir (confinamentos), e pode suscitar questões envolvendo a incolumidade física (vacinação obrigatória). ${ }^{9}$

\footnotetext{
${ }^{8}$ GRECO, Luis. Sobre o chamado Direito penal do inimigo. Revista da Faculdade de Direito de Campos, Ano VI, No 7, Dezembro de 2005. Disponível em http://fdc.br/Arquivos/Mestrado/Revistas/Revista07/Docente/07.pdf. Acesso em 29/06/2015, p.29.

${ }^{9}$ MENDES, Gilmar Ferreira; BRANCO, Paulo Gustavo Gonet. Curso de direito constitucional. São Paulo, Saraiva, 2014, p.268.
} 
Ora, Jakobs também utiliza de valores, princípios e direitos como forma de legitimar sua teoria de Direito Penal do Inimigo. Para ele, a segurança do próprio Estado por si só, legitimaria uma atuação firme frente ao "inimigo", como forma de evitar um estado selvagem. Neste sentido, podemos destacar que os principais "inimigos" dos países ocidentais atualmente, como o SIRI e o Talibã propõem uma destruição de um modo de viver e o fim de um Estado Democrático, criando nos territórios já conquistados um verdadeiro caos civilizatório, em que são mortos inocentes de toda sorte.

Neste sentido, o Estado tem o direito de garantir a segurança de cidadãos e estes têm o direito à segurança como forma de usufruir seus outros direitos como a liberdade e a propriedade e até mesmo garantir sua dignidade de pessoa humana. Portanto, em um conflito, os direitos fundamentais de um "inimigo" declarado do Estado não podem se sobrepor aos direitos também fundamentais de um Estado e de uma sociedade:

Certamente, o Estado tem direito a procurar segurança frente a indivíduos que reincidem persistentemente na comissão de delitos. Afinal de contas, a custódia de segurança é uma instituição jurídica. (...) Ainda mais: os cidadãos tem direito de exigir do Estado que tome medidas adequadas, isto é, têm um direito à segurança. ${ }^{10}$

A discussão possível será em relação à ponderação dos valores em jogo: a dignidade da pessoa humana presa, valores fundamentais como a vida de inocentes e, principalmente, o Estado Democrático e sua possibilidade de tratamento desigual perante a lei. Portanto, essa ponderação necessita de casos concretos e não simplesmente da adoção de um princípio em detrimento do outro, como argumentam os contrários da teoria do Direito Penal do Inimigo.

Em relação ao principio da igualdade, outro ponto de questionamento em relação à teoria de Jakobs, doutrinadores de grande renome como Cirino, afirmam que a desigualdade perante a lei de cidadãos e inimigos fere o princípio democrático no qual todos são iguais perante a lei.

\footnotetext{
${ }^{10}$ JAKOBS, Gunther; MELIÁ, Manuel Cancio. Direito penal do inimigo: noções e críticas. Porto Alegre: Livraria do Advogado Editora, 2012, p.42 e 43.
} 
A tese da desigualdade formal perante a lei entre cidadãos e inimigos contradiz o princípio democrático que inspirou as revoluções burguesas, fundadas na desigualdade real da relação capital/trabalho assalariado, mas instituídas sob a igualdade formal de uma legalidade geral aplicável a todas as pessoas, durante

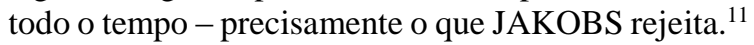

Todavia, outro autor, Dworkin afirma que a igualdade e a liberdade são desejáveis, contudo, só se pode ter uma a custo da outra e, neste sentido, a liberdade se sobrepõe à igualdade:

Igualdade e liberdade são ambos desejáveis, por exemplo, mas só podemos ter um à custa de outro. (...) É uma exigência soberana frente ao governo que ele trate todos aqueles sujeitos a seu domínio como iguais, ou seja, com igual consideração (...) Mas somos também informados que igual consideração requer o respeito pela liberdade das pessoas da mesma forma. Então, a igual consideração requer uma reflexão acerca destas duas virtudes: o governo deve fazer uma difícil escolha e apenas dogmáticos insistiriam que a igualdade é sempre mais importante que a liberdade. ${ }^{12}$

Portanto, seria novamente uma colisão entre princípios, sendo que sob a perspectiva de liberdade ser para a maioria das pessoas de uma sociedade o viver em um ambiente seguro, a igualdade de tratamento penal poderia ser limitada. O próprio Jakobs afirma que o uso de sua teoria não tem como objetivo o "menor custo" ou o mais fácil, até por que não teria motivo o Estado colocar em xeque seus próprios fundamentos por fatos corriqueiros. O Direito Penal do Inimigo é simplesmente utilizado em um

\footnotetext{
${ }^{11}$ SANTOS, Juarez Cirino dos. O Direito penal do inimigo - Ou o Discurso do Direito Penal Desigual, Instituto de Criminologia e Política Criminal, ICPC, 2012. Disponível em http://icpc.org.br/wp-content/uploads/2012/05/direito_penal_do_inimigo.pdf. Acesso em 01/09/2015, p.12.

${ }^{12}$ DWORKIN, Ronald. Valores entram em conflito? Uma perspectiva de um "ouriço". Dosponível em: http://www.academia.edu/8306477/Valores_Entram_em_Conflito_Uma_Perspectiva_de_Ouri\%C3\%A7o_Ronald_Dworkin_. CAcessoe em: 02/02/2018. p. 129 e 130.
} 
conflito de interesses em que o interesse da sociedade se sobrepõe em relação ao direito individual.

O Estado não tem porque colocar em jogo, de forma negligente, a sua configuração. Quando se fala em Direito Penal do Inimigo, isto não significa "Lei do menor esforço", "penas por meros indícios ou suspeitas" ou, inclusive "esquartejamento público para intimidação, ou coisas similares. ${ }^{13}$

Outro ponto questionável da teoria é a desumanização do inimigo, em que foram feitas comparações entre o Direito Penal do Inimigo e o nazismo, principalmente devido ao argumento de o Estado taxar pessoas. Uma comparação apesar de compreensível, não pode ser considerada correta, conforme ensina Greco:

Afirmar que o estado tem o dever de não respeitar seres humanos como pessoas é nada menos do que um escândalo. E por isso é também compreensível que se tenham feito comparações com a recente história alemã, o que, se por um lado, não parece de todo correto - primeiramente, porque não apenas a ideologia racista do nacional-socialismo, mas também concepções estatais totalitárias, ainda que não racistas (como o fascismo e o comunismo) negam o devido respeito a "indivíduos perigosos", e em segundo lugar, porque em lugar algum a raça é considerada um indício da falta de segurança cognitiva do indivíduo - por outro, releva com clareza o caráter autoritário da idéia. ${ }^{14}$

Interessante notar que nesta linha de conflito de direitos e da despersonalização de indivíduos, Jakobs argumenta que muitas leis já utilizam métodos que despersonalizam vítima civis, sendo considerados "danos colaterais". Cita como exemplo o $§ 14$, parágrafo $3^{\circ}$ da Lei de Segurança Aérea, na qual é lícito abater uma aeronave que pretende ser usada para atentar contra vidas humanas. Nota-se que tal dispositivo também é utilizado em

13 JAKOBS, Gunther; MELIÁ, Manuel Cancio. Direito penal do inimigo: noções e críticas. Porto Alegre: Livraria do Advogado Editora, 2012, p. 100 e 101.

${ }^{14}$ GRECO, Luis. Sobre o chamado Direito penal do inimigo. Revista da Faculdade de Direito de Campos, Ano VI, No 7, Dezembro de 2005. Disponível em http://fdc.br/Arquivos/Mestrado/Revistas/Revista07/Docente/07.pdf. Acesso em 29/06/2015, p. 230. 
outras nações, inclusive a nossa, como se vê na Lei no 9614/98, a qual afirma que esgotados os meios coercitivos legalmente previstos, a aeronave será classificada como hostil, ficando sujeita à medida de destruição. Assim, como ficariam as outras pessoas que estão nesta aeronave e que não estão participando da conduta criminosa? Para Jakobs, se o Estado pode sacrificar vidas inocentes por extrema necessidade, não se pode impedir de usar tais medidas para indivíduos que geraram tal situação.

Portanto, se o Estado, em caso de extrema necessidade, inclusive frente a seus cidadãos que são responsáveis por ela, não conhece tabu algum, mas sim faz o necessário, menos ainda poderão ser impostos tabus no âmbito das medidas para se evitar essa extrema necessidade dirigida contra terroristas. ${ }^{15}$

A utilização do próprio termo inimigo seria, segundo alguns autores, a tentativa de Jakobs em legitimar um direito penal de guerra. Portanto, um direito que possibilita ao Estado eliminar determinado indivíduo em prol da preservação da ordem jurídica.

Jakobs revela - quiça inconscientemente - o seu verdadeiro propósito, que é legitimar um direito penal de guerra, um direito penal que adota uma postura belicosa, de combate, de eliminação, de destruição do próximo para manter estável uma ordem dada. Em resumo, de destruição do humano em prol da preservação da ordem jurídica. ${ }^{16}$

Também neste sentido, Cirino argumenta:

O duplo sistema de imputação de JAKOBS suprime seculares garantias constitucionais do Estado Democrático de Direito, como expressamente propõe: o processo contra o inimigo não precisa ter forma de Justiça (justizförmig), porque não é regido pelo

15 JAKOBS, Gunther; MELIÁ, Manuel Cancio. Direito penal do inimigo: noções e críticas. Porto Alegre: Livraria do Advogado Editora, 2012, p. 106.

${ }^{16}$ MUÑOZ CONDE, Francisco; BUSATO, Paulo Cesar. Crítica ao direito penal do inimigo. Rio de Janeiro: Lumen Juris, 2011, p.192. 
processo legal devido; ao contrário, o processo contra o inimigo deve ter forma de guerra (kriegsförmi). ${ }^{17}$

Entretanto, podemos concluir que o conceito de guerra é que foi alterado com o tempo. Se em um passado remoto, guerra era a luta armada entre duas nações, hoje, a concepção é de um grupo ou organização cujo intuito é o de destruir uma ordem jurídica instalada. Neste sentido, organizações terroristas se assemelham a grupos de traficantes que tentam subverter a ordem de um país. Assim, Jakobs revela que a guerra existe, não é algo que tenta legitimar ou esconder, sendo necessário para tal situação um Estado que possa conduzir a sociedade nesta guerra.

Voltando novamente à questão proposta no início: pode-se conduzir uma guerra contra o terror com os meios de um Direito Penal próprio de um Estado de Direito? Um estado de Direito que abarque tudo não poderia conduzir essa guerra, pois teria que tratar seus inimigos como pessoas, e, correspondentemente, não poderia trata-los como fontes de perigo. Na prática, as coisas são diferentes no Estado de Direito ótimo, e isso lhe dá a possibilidade de não ser atingido por ataques de seus inimigos. ${ }^{18}$

Por fim, existe um argumento contundente da doutrina contrária à teoria de Jakobs, a qual não há contra-argumento: a possibilidade desta teoria legitimar sistemas autoritários e de governos que buscam um criminoso imaginável dos problemas sociais.

Não obstante, como se pode ver, o problema desse silogismo está na natureza das premissas que o estruturam, premissas que podem corresponder às preferências pessoais de JAKOBS, mas que cancelam princípios jurídicos civilizados separando a população entre cidadãos e inimigos, tudo conforme sentimentos idiossincráticos ou opções ideológicas deste ou daquele

\footnotetext{
17 SANTOS, Juarez Cirino dos. O Direito penal do inimigo - Ou o Discurso do Direito Penal Desigual, Instituto de Criminologia e Política Criminal, ICPC, 2012. Disponível em http://icpc.org.br/wp-content/uploads/2012/05/direito_penal_do_inimigo.pdf. Acesso em 01/09/2015, p.11.

18 JAKOBS, Gunther; MELIÁ, Manuel Cancio. Direito penal do inimigo: noções e críticas. Porto Alegre: Livraria do Advogado Editora, 2012, p. 113.
} 
funcionário do Sistema de Justiça Criminal, com a consequência de reinstituir o proscrito Direito penal do autor. ${ }^{19}$

Todavia, da mesma forma que existe a possibilidade de o Direito Penal do Inimigo legitimar estados injustos de exceção, a falta de credibilidade das normas jurídicas, provocada pela banalização da pena e a continuidade criminosa, também é um risco de manutenção de uma sociedade, pois invariavelmente leva a um estado de anarquia, uma regressão ao "direito do mais forte".

\section{CONSIDERAÇÕES FINAIS}

Sem dúvida, o Direito Penal do Inimigo traz em uma primeira impressão, um sentimento de aversão e condenação à teoria, devido aos riscos inerentes a princípios consagrados no Estado Democrático de Direito como o princípio da dignidade da pessoa humana ou o princípio da igualdade.

Todavia, em uma análise mais contida em relação aos próprios institutos constitucionais, como por exemplo, a hermenêutica constitucional, a ponderação de princípios e a colisão de direitos fundamentais demonstram que a teoria do Direito Penal do Inimigo possui uma base teórica lógica em um sistema que privilegia o Estado Democrático de Direito.

A dúvida e os questionamentos de uma possível transformação de um Estado Democrático de Direito em um Estado Policial são claros e evidentes. Todavia, no campo jurídico, principalmente hermenêutico, os argumentos contra a teoria pecam em sua essência.

Portanto, acima de ataques ou defesas sentimentais, a teoria é necessária para uma visão clara do instituto, que a princípio pode ser entendido cabível em um Estado Democrático de Direito, desde que sua ação seja sempre uma exceção e não, uma regra estatal.

${ }^{19}$ SANTOS, Juarez Cirino dos. O Direito penal do inimigo - Ou o Discurso do Direito Penal Desigual, Instituto de Criminologia e Política Criminal, ICPC, 2012. Disponível em http://icpc.org.br/wp-content/uploads/2012/05/direito_penal_do_inimigo.pdf. Acesso em 01/09/2015, p.10. 


\section{REFERÊNCIAS BIBLIOGRÁFICAS}

DWORKIN, Ronald. Valores entram em conflito? Uma perspectiva de um "ouriço". Dosponível em: http://www.academia.edu/8306477/Valores_Entram_em_Conflito_Uma_Perspectiva_de_Ouri\%C3\%A7o_Ronald_Dworkin_. CAcessoe em: 02/02/2018

FERNANDES, Bernardo Gonçalves. Curso de direito constitucional. Salvador. Editora Juspodivm, 2015.

GRECO, Luis. Sobre o chamado Direito penal do inimigo. Revista da Faculdade de Direito de Campos, Ano VI, No 7, Dezembro de 2005. Disponível em http://fdc.br/Arquivos/Mestrado/Revistas/Revista07/Docente/07.pdf. Acesso em 29/06/2015.

GRECO, Rogério. Direito penal do equilíbrio. 8.ed. Rio de Janeito: Impetus, 2015.

JAKOBS, Gunther; MELIÁ, Manuel Cancio. Direito penal do inimigo: noções e críticas. Porto Alegre: Livraria do Advogado Editora, 2012.

MENDES, Gilmar Ferreira; BRANCO, Paulo Gustavo Gonet. Curso de direito constitucional. São Paulo, Saraiva, 2014.

MUÑOZ CONDE, Francisco; BUSATO, Paulo Cesar. Crítica ao direito penal do inimigo. Rio de Janeiro: Lumen Juris, 2011.

SANTOS, Juarez Cirino dos. O Direito penal do inimigo - Ou o Discurso do Direito Penal Desigual, Instituto de Criminologia e Política Criminal, ICPC, 2012. Disponível em http://icpc.org.br/wp-content/uploads/2012/05/direito_penal_do_inimigo.pdf. Acesso em 01/09/2015. 